\title{
İyi Bir Sistematik Derleme Nasıl Yazılmalı?
}

\section{How Should a Good Systematic Review be Written?}

\author{
${ }^{1}$ Nursan ÇINAR \\ ${ }^{1}$ Sakarya Üniversitesi Sağlık Bilimleri Fakültesi Çocuk Sağlığı ve Hastalıkları Hemşireliği, Sakarya, Türkiye \\ Nursan Çinar: https://orcid.org/0000-0003-3151-9975
}

\begin{abstract}
ÖZ
İyi bir sistematik derleme, ilgilenilen araştırma sorusu için var olan tüm kanıtların bir arada bulunacağı eşsiz bir kaynaktır. Literatür taraması daha detaylı yapıldığı ve yazarın önyargısı daha az olduğu için sistematik derlemeler altın standart olarak kabul edilmektedir. Sistematik derleme çalışmaları kanıt yönünden üstün olmakla birlikte, sistematik derleme yöntembilime uygun olarak yapılmadığında ve raporlandırılmadığında bias riski artar. Karar vericiler için sınırlı bilgi oluşturur. Uygun yöntem ile yapılmış yüksek düzeyde sistematik derlemeler in sağlık hizmetlerinin sunumuna büyük değer katacağını bilerek sistematik derleme yapmayı ögrenmek sağlik profesyonelleri için önemli bir hedef olmalıdır. Bu makalede iyi bir sistematik derleme yazımı ile ilgili bilgi ve tecrübeler paylaşılmaktadır.
\end{abstract}

Anahtar Kelimeler: Araştırma sorusu, raporlama, sistematik derleme, yöntembilim

\begin{abstract}
A good systematic review is a unique resource where all available evidence for the research question of interest can be found together. Systematic reviews are considered the gold standard because the literature review is more detailed and the author's bias is less. Although systematic review studies are superior in evidence, when not done and reported in accordance with the systematic review methodology, the risk of bias increases and creates limited information for decision makers. Learning to do systematic reviews should be an important goal for healthcare professionals, knowing that highly systematic reviews with appropriate methodology will add great value to the delivery of healthcare services. In this article, knowledge and experiences about writing a good systematic review are shared .

Keywords: Methodology, reporting, research question, systematic review
\end{abstract}

Sorumlu Yazar / Corresponding Author:

Nursan Çınar

Sakarya Üniversitesi, Sağlık Bilimleri Fakültesi, Çocuk Sağlığı ve Kabul Tarihi/ Accepted: 21/03/2021

Hastalıkları Hemsirleiği Anabilim Dalı, Esentepe Kampüsü, 54187, Online Yayın Tarihi/ Published: 05/06/2021

Sakarya, Türkiye

Tel: 02642956621

Email: ndede@sakarya.edu.tr

Atıf/ Cited: Çınar N. İyi Bir Sistematik Derleme Nasıl Yazılmalı? Online Türk Sağllk Bilimleri Dergisi 2021;6(2):310-314. doi: 10.26453/otjhs.888569

\section{GİRIŞ}

Sistematik Derleme (SD), belli bir konuda hazırlanmış araştırma sorusuna yanıt bulmak için, belirlenmiş ölçütlere uygun olarak aynı konuda yapılmış çalışmaların sistemli ve yan tutmadan taranması, bulunan çalışmaların geçerliğinin değerlendirilmesi ve sentezlenerek birleştirilmesidir. Sistematik derleme, uygun şekilde yapıldığında ve rapor edildiğinde, sağlık hizmetinin bilgi tabanına çok büyük değer katar. Sistematik derleme ve meta-analizler kanıt piramidinin en üst basamağında yer alır ve klinik uygulama kılavuzları için çıkarımlar yapılabilir. Sağlık alanındaki kaynakların fazlalığı ve araştırmacıların zamanının kısıtlılığı düşünüldüğünde derlemelerin karar vermede ne kadar önemli bir role sahip olduğu anlaşılır. Aynı zamanda sistematik derlemeler ile gelecekte araştırılması gereken konu- lar, literatürde ki boşluklar ya da yetersizlik alanları da tanımlanabilmektedir. İyi bir derleme, ilgilenilen araştırma sorusu için var olan tüm kanıtların bir arada bulunacağı eşsiz bir kaynaktır. Daha detaylı literatür taraması içerdiği ve yazarın önyargısı daha az olduğu için sistematik derlemeler altın standart olarak kabul edilmektedir. ${ }^{1-5}$

Unutmamalıdır ki bir sistematik derlemenin amacı yalnızca tüm bilgileri toplamak değildir.

İlgili çalışmaları kapsamlı bir biçimde tarayıp çeşitli kabul ve ret ölçütleri kullanarak hangi çalışmaların derlemeye gireceğini tarafsız bir şekilde belirleyip bu çalışmalarda yer alan bilgilerin sentez edilmesi ile oluşturulur.

Sistematik derleme çalışmaları kanıt yönünden üstün olmakla birlikte, sistematik derleme metodolojisine uygun olarak yapılmadıklarında ve raporland1- 
rılmadıklarında bias riski artar ve karar vericiler için sınırlı bilgi oluştururlar. Özellikle kapsama alınan çalışmaların metodolojik kalitesindeki yetersizlikler ve raporlamadaki sorunlar, araştırma sonuçlarının yorumlanma ve genellenmesinde yetersizliğe ya da çelişkilere yol açarak klinik karar için güçlü kanıt oluşturmazlar.

İyi bir sistematik derleme yazarı SD metodolojisinin en temel aşamalarını yerine getirir:

- Araştırma sorusunu oluşturur.

- Dahil etme ve hariç tutma kriterlerini belirler.

- Protokol yapar.

- Açık ve tekrarlanabilir bir yöntem kullanır. Kapsamlı literatür taraması yapar.

- Uygun verilerin kalitesini ve geçerliliğini değerlendirir.

- Bulguları sistematik olarak sentezler, yorumlar ve raporlar. ${ }^{1-3,6,7}$

\section{ARASTIRMA SORUSUNUN FORMÜLE EDIL- MESI}

İyi bir sistematik derleme yapmanın ilk adımı açık, net ve yapılandırılmış bir soru şeklinde ele alınması gereken sorunu tanımlamaktır. Özellikle, arama stratejisi derleme sorusu üzerine kurulduğu için, derleme sorusunu formüle etmek, arama stratejisini geliştirmek için çok önemlidir. Bir derlemenin "nasıl" hazırlanacağını sormadan önce "neden" hazırlanacağını sormak akıllıcadır. Derlemeyi hemen yazmaya başlamak çekici de olsa, önemli soruların neler olduğunu belirlemek için geçireceğiniz zaman asla boşa gitmeyecektir. ${ }^{2,7,8}$

Sorular, kanıta dayalı uygulamaların arkasındaki itici güçtür. Kanıta dayalı uygulama soruları, gerçek sorunlara odaklanır. Kanıta dayalı uygulamaların en zorlu yönlerinden biri, cevaplanabilir soruyu gerçekten belirlemektir. Soruyu tanımlama becerisi, soruyu yanıtlamak için ilgili bilgileri bulmak için çok önemlidir. İlgili bilgilerin başarılı bir şekilde alınma$\mathrm{S}$, açıkça tanımlanmış, iyi yapılandırılmış bir soruyla başlar. Soru sormak için standart bir format veya çerçeve, temel unsurlara odaklanmaya yardımcı olur. Soru oluşturma aynı zamanda bir düşünme dönemi de sağlar. Gerçekten aradığım bilgi bu mu? Neden bu bilgiyi arıyorum? Soruları üzerine düşünmemizi sağlar. ${ }^{2,7,8}$

İyi bir araştırma konusu seçmek kolay olmayabilir.

- İlgilendiğiniz bir konuyu seçtikten sonra, kapsaml1 bir arama yapmayı yararlı bulabilirsiniz.

- Bu önemli tartışmalar ve güncel konular hakkında bilgi edinmenize ve araştırma sorunuza daha iyi odaklamanıza olanak sağlayacaktır.
- Sorunun çok geniş veya çok dar olması durumunda, konunun araştırılması çok zor olacaktır. Çoğu durumda geniş bir konuyla başlayacaksınız. Daha sonra yönetilemez miktarda bir literatüre ulaşırsanız onu daraltmanız gerekebilir. Konunuzu daraltmanın birkaç yolu vardır:

- Belirli bir coğrafi bölge, zaman dilimi veya nüfus seçilebilir.

- Konunun belirli bir yönünü seçilebilir veya kilit konulara veya güncel tartışmalara odaklanılabilir.

Standart SD sorusu PICO(S) içerir: PICO kavramı klinik soruları aranabilir anahtar kelimelere ayırmak için 1995 yılında Richardson ve arkadaşları tarafından tanımlanmıştır. ${ }^{9}$ Schardt ve ark. soru tipine ve bu belirli soruyu cevaplamak için en iyi çalışma tasarımına atıfta bulunmuşlar ve PICO (S) modelini sunmuşlardır. $^{10}$

PICO (S) modelinin bir arama stratejisi aracı olarak kullanılması literatür taramalarının kalitesini arttırır. Araştırma sorusunun çerçevesi belirlenir. Araştırma sorusu katılımcıları (P: Population), müdahaleleri (I: Interventions), karşılaştırma gruplarını (C: Comparators), sonuçları (O: Outcomes) ve araştırma desenlerini(Hangi çalışma tasarımlarının soruyu cevaplamak için uygun olduğunu belirler) (S: Study designs) açıkça tanımlamalıdır. Araştırma sorusunun bu bileşenleri kısaca PICOS olarak adlandırılmaktadir. ${ }^{1,2,7,8,10}$

Örnek:

Başlık: Dondurma ve Çözdürmenin Olgun Anne Sütünün İçeriğine Etkileri: Sistematik Derleme ${ }^{12}$

Araştırma sorusu: Dondurma ve çözdürme olgun anne sütünün içeriğini etkiler mi?

Katılımcıların Türü (P: Population): Miadında (38.gestasyon haftasını tamamlamış) doğum yapan annelerden alınan olgun süttür.

Müdahalelerin Türü (I: Interventions): Dondurulan $\left(-18\right.$ veya $-20^{\circ} \mathrm{C}$ 'de) ve çözdürülen olgun anne sütünün içerik analizidir.

Karşılaştırma Grupları (C: Comparators): Miadında doğum yapmış annelerden alınan olgun taze (3-24 saat) sütlerdir.

Ölçülen Sonuçlar (O: Outcomes): Olgun taze anne sütü içeriği ile dondurma ve çözdürme yapılan olgun anne sütü içeriğinin (makrobesin, mikrobesin ve biyoaktif içerik) karşılaştırılmasıdır.

Araştırma Desenleri (S: Study designs): Randomize kontrollü deney ve prospektif kohort çalışmalardır.

Sistematik derleme sorusu tanımlandıktan sonra değişiklik yapılmamalıdır. Yazarlar formüle edilen sorunun klinik olarak alakalı, yeni ve ilginç olmasını sağlamalıdır. 


\section{DAHILL ETME VE HARIÇ TUTMA KRITER- LERINII BELIRLEME}

Çalışma sorusu kesinleştirildiğinde, yazarlar kapsamlı bir dahil etme ve hariç tutma kriterleri listesi oluşturmalıdır. Araştırma sorununun bileşenleri dikkate alınarak dâhil etme ve dışlama kriterleri (inclusion and exclusion criteria) tanımlanır. ${ }^{4,5} \mathrm{Se}-$ çim yanlılığını önlemek için, veri toplama ve analizden önce dahil etme ve hariç tutma kriterleri üzerinde anlaşıılmalıdır.

- Dahil edilecek uygun makaleleri belirlemek için katı kriterler gereklidir. ${ }^{1}$

- Sistematik Derleme yaparken, yazarların seçecekleri ve hariç tutacağı çalışmaları açıkça tanımlamaları çok önemlidir.

- Literatürde iyi temsil edilen konular için mevcut kanıtları sentezlemeyi hedefliyorsanız, yalnızca yüksek düzeyde kanıt içeren makaleleri (Düzey I ve II) dahil etmelisiniz.

- Bununla birlikte, eğer derleme sorusu ile ilgili alanda çok fazla çalışma yapılmamışsa, daha sonra düşük düzeyli çalışmaları dahil etmek de akıllıca olacaktır.

- Ayrıca makalenin dahil edileceği dile karar vermek önemlidir. Her ne kadar sadece İngilizce makalelerin alınması bias oluştursa da çeviri imkânlarının sınırlı olması sebebiyle sıklıkla tercih edilir.

- Yayın yılı sınırlaması yararlı olabilir. ${ }^{1,2,4,8}$

- Yalnızca insan çalışmalarının veya hem insan hem de hayvan çalışmalarının dahil edilip edilmeyeceği belirlenir. ${ }^{1,2,4,8}$

Protokol: Sistematik derleme çalışmaları önemli araştırma projeleridir ve belirli bir protokol dahilinde yapılması gerekmektedir. Sistematik derleme sürecinin belli bir plan ve protokol çerçevesinde planlanması ve yürütülmesi gerektiği hem uluslararası kanıt merkezlerinin raporlarında, hem de yayınlarda belirtilmektedir. ${ }^{1-3,5}$

Protokol, önyargiyı en aza indirmek amaciyla derlemenin açı bir plan takip etmesini ve kullanılacak yöntemlerin belirtilmesini sağlar. ${ }^{5}$ PROSPERO (International Prospective Register of Systematic Review) İngiltere Ulusal Sağlık Araştırmaları Enstitüsü tarafindan finanse edilen sistematik derleme kaylt sistemidir. PROSPERO; duplikasyondan kaçınmaya ve protokolde planlama aşaması tamamlanmış çalışmalarla karşılaştırmasına olanak tanıyarak bias riskini azaltmaya yardımcı olmak ve kayıtlı sistematik derlemelerin kapsaml bir listesini sağlamayı amaçlamaktadır. Aynı zamanda devam eden sistematik derlemeler hakkındaki bilgilere serbest ve açık erişim sağlayarak sistematik derleme sürecinde şeffaflı̆̆ı teşvik eder ve konunun istenmeyen bir şekilde tekrarlanmasını önlemeye yardimci olur. ${ }^{2,11}$

Sistematik derlemelerde «PROSPERO registered number» isteyen dergileri sayısı giderek artmaktadır. PROSPERO her kayitlı sistematik derleme için bir kayıt numarası verir. Bu numara, yayınlarda ve raporlarda gösterilebilir. Bu numara derlemenin daha sonraki kullanımını takip etmeye ve etkilerini izlemeye de olanak sağlar.

\section{Örnek:}

İncelemeye başlamadan önce, çalışmanın protokolü sistematik derleme ve meta-analizlerin kayıt altına alınmasını sağlayan "PROSPERO" veri tabanına kaydedilmiştir $\quad(\mathrm{ID}=\mathrm{CRD} 42020172569$; https:// www.crd.york.ac.uk/prospero/display_record.php? RecordID $=172569) .{ }^{11,12}$

\section{KAPSAMLI LITERATÜR TARAMASI}

Belli bir konu hakkında önemli bilgi içeriği olan yayınların/belgelerin (kitap, makale, süreli yayın, gazete vb.)sistematik olarak gözden geçirilmesi ve kritik edilmesi olarak tanımlanır. İyi yapılandırılmış bir literatür araştırması, araştırılan konuyla ilgili sağlam kanıtları bulmanın en etkili ve verimli yoludur. Arama sürecindeki kilit rol anahtar kelimelere düşmektedir. Anahtar kelimelerin keşfedilmesi kadar doğru kullanılmaları da önemlidir. Anahtar kelimelerin oluşturulmasında araştırma soruları temel alınmalıdır. İngilizce anahtar kelimeler için MeSH (Medical Subjects Headings) ve İngilizce anahtar kelimelerin Türkçe karşılığını oluşturmak için Türkiye Bilim Terimleri (TBT) (https:// www.bilimterimleri.com/) içeriğinden yararlanılabilir. ${ }^{2,4,5}$ Taramayı daraltabilmek adına anahtar kelimeler birlikte kullanılmanın ötesinde yan yana kullanılıyorlarsa kelime grubu iki tırnak işaretinin (“" ”) arasına yazılmalıdır.

Boolean bağlaçları (Boolean connectors: and,or,not) "ve", "veya", "değil" kullanılarak alan sınırlandırılabilir. "Ve" tüm arama terimlerini içeren sonuçları alır; "veya" sonuçların arama terimlerinin en az birini içermesi gerektiği anlamına gelir. Seçilen "değil" terimle ilgili alıntıları hariç tutar. ${ }^{5}$ Literatür taraması akademik araştırmaların en önemli bölümünü oluşturur. Bu aşamada bilinçli ve doğru olarak atılan her adım araştırmacıya bilimsel yönden fayda sağlayarak sonuca ulaştırır. Bibliyografik yazılım (Örnek: EndNote, Reference Manager) kullanılarak elde edilen araştırmalar kayıt edilir ve depolanır. ${ }^{4}$ 


\section{VERİ TABANININ SEÇILMESI}

Konuyu seçtikten ve daralttıktan sonra, bir sonraki adım arama için en uygun veri tabanlarını seçmektir. Arama yapmak için veri tabanlarını belirlemek (The Cochrane Library, MEDLINE; CINAHL vb) yazarlar için kritik makaleleri gözden kaçırmamak için önemli bir karardır. ${ }^{5}$

Örnek: Aşağıdaki anahtar kelimeler kullanılarak tarama bileşimi oluşturulmuştur.

- Dondurma, çözdürme (freezing AND thawing).

- Anne sütü, insan sütü, olgun anne sütü, emzirme, içerik,etki ("breast milk" OR "human milk" OR "mature breast milk" OR "breastfeeding") AND ("contains" OR "effect").

Tarama kombinasyonu: (freezing AND thawing) AND ("breast milk" OR "human milk" OR "mature breast milk" OR "breastfeeding") AND ("contains" OR “effect").

Taramalar için belirtilen anahtar kelimeler doğrultusunda MEDLINE, Web of Science, Pubmed, Science Direct, CINAHL, Scopus, Cochrane, TÜBİTAK, Medline- Türk veri tabanı kullanılmıştır. Ayrıca tez veri tabanları olarak ProQuest ve YÖKTEZ kullanılmıştır. ${ }^{12}$

\section{UYGUN VERILERIN ÇEKILMESI VE KALİ-} TESININ INCELENMESI

PRISMA akış diyagramına göre seçim süreci üç basamaktan oluşmaktadır. Bu basamaklar çalışmanın başlık, özet ve tam metinlerinin değerlendirilmesini kapsar. Derleme sürecinde metodolojik kalite ile birlikte derlemenin raporlama kalitesinin artırılması için en temel öneri, hem derlemenin yürütüldüğü hem de yayın aşamasında derleme yöntemine uyulduğunu gösteren standardize araçları kullanmaktır. Çalışmanın kalitesinin değerlendirilmesi, sistematik derlemenin ortaya koyduğu kanıtın gücünün bir göstergesidir ve gelecek araştırmalar için gerekli standartlar hakkında bilgi verir. Bu konuda uluslararası kuruluş ve deneyimli yazarlar tarafından geliştirilen, 27 maddelik bir kontrol listesi ve dört aşamalı akış diyagramı olan PRISMA Bildirgesi'nin (The Preferred Reporting Items for Systematic reviews and Meta-analysis) kullanılması ve bu bildirgedeki maddelere uyum önerilmektedir. ${ }^{13}$ Cochrane Sistematik Derlemeler Rehberi ise Sistematik derleme ve Meta-analiz yürütenler için temel bir kaynaktır. Kalite değerlendirme aracının belirlenmesinde sistematik derlemeye dahil edilen araştırmaların deseni dikkate alınmalıdır. Gerekirse bir sistematik derlemede birden fazla kalite değerlendirme aracı kullanılabilir.
Her bir çalışma için kalite değerlendirmeleri birbirinden bağımsız bir şekilde en az iki araştırmacı tarafından yürütülür. Bu araçlar ile çalışmaların metodolojik kalitesini "zayıf", "orta" ve "güçlü" olarak sınıflandırılabilmektedir. Değerlendirme sonucunda "güçlü" ve "orta" puan alan çalışmalar, sistematik derlemeye dahil edilir. Araştırma kalitesini değerlendiren araştırmacılar eş zamanlı olarak kodlamayı da gerçekleştirebilir. ${ }^{1,2,4,5,8,12,13}$

Raporlama: Sistematik derleme ya da meta-analiz raporlanırken PRISMA kuralları kullanılmalıdır.

PRISMA'nın kullanılması derleme raporunun kalitesini iyileştirmektedir. Böylece raporlanmada uluslararası standart sağlanabilir. Ayrıca Yazarlar PRISMA'yı derlemeyi yürütmek için bir çerçeve olarak da kullanabilirler. Akış diyagramında yazı ile birlikte şekil olarak da sunulmalıdır. Yazarlar sistematik derleme bulgularında; çalışma seçiminin bir raporunu, çalışmaların özelliklerini, çalışmalarda yan tutma riskinin (bias) analiz sonuçlarını ve çalışmaların sentezlenmiş bulguları sunmalıdır. Tablolar bulguları sunmak için tercih edilen bir yöntemdir. ${ }^{1,4,5,8,13}$

Tartışmada yazarlar kanıtın gücü ile birlikte çalışmanın kanıtlara nasıl katkıda bulunduğunu ifade etmelidir. Ayrıca tartışma bölümümü çalışmalardaki yan tutma, çalışmaların alınmasındaki zorluklar ve sınırlılıkları da içermelidir.

\section{SISTEMATIK DERLEMELERIN GÜNCEL- LENMESI}

Sistematik derleme güncellemeleri, daha önce yayınlanmış sistematik derlemenin güncel hale getirir. Bir güncelleme için yol gösterici ilke, orijinal sistematik derlemenin (veya daha önce güncellenmiş derlemenin) yürütülmesi ve raporlanmasından ayrı olmas1dır. Güncellenen derleme bağımsız bir yayın olacaktır. Orijinal sistematik derleme yayınının (veya daha önce güncellenmiş derlemenin) bir parçası olmayacaktır. Yazarlar daha önce yayınladıkları çalışmaları güncellediklerini açıkça belirtmeli ve bunlara atıfta bulunmalidirlar.

Güncellemenin gerekçesi "yeni kanıtları"' belirleme çabasıdır. Genel olarak "yeni kanıtlar" daha önce tamamlanmış derlemeye dahil edilmemiş kanıtlar. Örneğin, yeni kanıtları tanımlamak için ek bir veri tabanı (MEDLINE ve MEDLINE ve EMBASE) kullanılması güncelleme olarak kabul edilir. Alternatif olarak güncelleme, orijinal (veya daha önce güncellenmiş) sistematik derlemenin tamamlanmasının üzerinden belirli bir süre geçtikten sonra başlatılabilir (bu süre zarfında ortaya çıkan yeni kanıtların be- 
lirlenmesi amacıyla). Zaman, güncelleme işleminin başlatılması için bir tetikleyici veya gösterge olabilir.

\section{TARTISYMA VE SONUÇ}

Sistematik bir derlemeyi yürütmek ve yayımlamak sistematik derleme yazmada tecrübeli bir araştırmacının da olduğu bir araştırma ekibi, ekip üyeleri arasında iş birliği, planlama aşamasından itibaren sistemli bir çalışma, zaman ve samimi çaba gerektirir.1,2,4,6 Standartlara uygun yapilmayan sistematik derlemelerin okuyucu beklentilerine cevap vermesi beklenemez. Buna karşın iyi yapılandırılmış ve standartlara uygun yapılmış sistematik derlemeler kanıt piramidinin en üst basamağında yer alır ve ilgilenilen araştırma sorusu için mevcut kanıtları bir arada sunan eşsiz bir kaynaktır.

Etik Komite Onayı: Bu çalışma Editör davetli derleme yazısıdır. Etik kurul iznine gerek yoktur.

Çıkar Çatışması: Yazar tarafından herhangi bir çıkar çatışması bildirilmemiştir.

Yazar Katkıları: Fikir-NÇ; Denetleme-NÇ; Yazıyı yazan-NÇ.

Hakem değerlendirmesi: Dış bağımsız.

\section{KAYNAKLAR}

1. Yannascoli SM, Schenker ML, Carey JL, Ahn J, Baldwin KD. How to write a systematic review: A step-by-step guide. University of Pennsylvania Orthopaedic Journal. 2013;23:6469.

2. Uman LS. Systematic reviews and metaanalyses. Journal of the Canadian Academy of Child and Adolescent Psychiatry. 2011;20(1):57 -59 .

3. Chung KC, Burns PB, Kim HM. A practical guide to meta-analysis. The Journal of Hand Surgery. 2006;31(10):1671-1678. doi:10.1016/ j.jhsa.2006.09.002

4. Karaçam Z. Sistematik derleme metodolojisi: sistematik derleme hazırlamak için bir rehber. Dokuz Eylül Üniversitesi Hemşirelik Yüksekokulu Elektronik Dergisi. 2013;6(1):26-33.

5. Oermann MH, Hays JC. Writing for publication in nursing. In: Karaçam Z. ed. .Elif Gürsoy, Hemşirelikte yayın yazarlığı içerisinde ve kanıta dayalı uygulama makaleleri. 10 th ed. Ankara, Nobel Tip Kitabevi; 2020:135-155.

6. Molle AM, Myles PS. What makes a good systematic review and metaanalysis? British Journal of Anaesthesia. 2016; 117 (4): 428-30. doi:10.1093/bja/aew264.

7. Davies KS. Formulating the evidence based practice question: a review of the frameworks. Evidence Based Library and Information
Practice. 2011;6(2):75-80. doi:10.18438/ B8WS5N

8. Khan KS, Kunz R, Kleijnen J, Antes G. Five steps to conducting a systematic review. Journal of the Royal Society Of Medicine. 2003;96 (3):118-121. doi:10.1258\%2Fjrsm.96.3.118

9. Richardson WS, Wilson MC, Nishikawa J. Hayward RSA. The well-built clinical question: A key to evidence-based decisions. ACP Journal Club. 1995;123:A12-13. doi:10.7326/ACPJC1995-123-3-A12

10. Schardt C, Adams MB, Owens T, Keitz S, Fontelo P. Utilization of the PICO framework to improve searching PubMed for clinical questions. BMC Medical Informatics and Decision Making. 2007;7:16. doi:10.1186/14726947-7-16

11. National Institute for Healt Research PROSPERO. https://www.crd.york.ac.uk/ prospero/. Erişim tarihi 28 Şubat 2021.

12. Yıldız Kaya Ö. Dondurma ve çözdürmenin olgun anne sütünün içeriğine etkileri: sistematik derleme. Sakarya Üniversitesi Sağlık Bilimleri Enstitüsü Hemşirelik Anabilim Dalı, Yüksek Lisans Tezi, Sakarya, Türkiye. 2020.

13. Nahcivan N, İncirkuş K. Türkiye'de hemşirelik dergilerinde yayınlanan sistematik derlemelerin raporlama özellikleri. Hemşirelikte Eğitim ve Araştırma Dergisi. 2018;15:106-16. 